\title{
Determination of fluoranthene, benzo[b]fluoranthene and benzo[a]pyrene in meat and fish products and their intake by Malaysian
}

\begin{abstract}
Forty-two types of meat and fish products widely consumed by Malaysian population were analyzed for three high molecular weight polycyclic aromatic hydrocarbons (PAHs) namely, fluoranthene, benzo[b]fluoranthene and benzo[a]pyrene using high performance liquid chromatography with fluorescence detector. Dietary intake of sum of the three PAHs was then estimated for the population by interviewing 600 respondents aged above 18 years old using food frequency questionnaire. The highest level of individual PAHs was found to be fluoranthene $(219.74 \mathrm{ng} / \mathrm{g})$, whereas the lowest level was benzo[a]pyrene $(24.33 \mathrm{ng} / \mathrm{g})$. Grilled beef satay showed the highest total PAHs $(66.28 \mathrm{ng} / \mathrm{g})$ among the all food products. The mean dietary intake of the sum of three PAHs by Malaysian was $297.58 \mathrm{ng} / \mathrm{day}$.
\end{abstract}

Keyword: Fluoranthene; Benzo[b]fluoranthene and benzo[a]pyrene; Fish; Meat and meat products; Dietary intake; Food frequency questionnaire (FFQ) 